\section{HONOURS, AWARDS, APPOINTMENTS}

New Chair of CCHDS

Bernie Speculand, Oral and Maxillofacial Surgeon, has been elected as the new Chair of the British Dental Association's (BDA's) Central Committee for Hospital Dental Services (CCHDS) for the 2012/14 triennium. Mr Speculand is a consultant at University Hospital Birmingham and was viceChair of CCHDS in the last triennium.

\section{First NICE award to a dentist}

Dr Liz Robb, Senior Special Care Dentist, University

Hospitals Bristol NHS Foundation Trust, has been awarded a three-year fellowship by the National Institute for Clinical Excellence (NICE). NICE has awarded 11 fellowships this year to professionals working in the NHS, social care and public health. For the first time since the programme began in 2010, NICE has welcomed professionals from dentistry, ophthalmology and sociology.

Dr Robb has a special interest in the equity of and access to care, particularly of the elderly. She is also the Clinical Governance lead for the UHBristol Primary Care Dental Service.

\section{ARMY DENTIST MADE BDA PRESIDENT}

A retired army dentist has been installed as the 126th President of the British Dental Association (BDA). Dr Frank Holloway is the first armed forces dentist to receive this honour since 2003.

Dr Holloway was presented with his chain of office and made his inaugural speech on Thursday 26 April at the opening of the 2012 British Dental Conference and Exhibition at the Manchester Central Convention Complex.

Dr Holloway qualified as a dentist from Bristol University and gained his Licence in Dental Surgery from the Royal College of Surgeons in 1969.

After five years in general practice in the UK, he worked for the US Army in Bavaria as a civilian dentist. Three years later he joined the British Army, subsequently working in Germany, Texas, Cyprus, the Outer Hebrides and occasionally in England. He achieved the rank of Colonel and completed his regular army service as Commandant of the Royal Army Dental Corps, Commanding Officer of the Defence Dental Services Training Centre and Principal Dental Officer of the Home Counties region. He spent the last five years of his career treating new recruits and recently retired after 33 years in the army.

Dr Holloway has been a member of the BDA's Armed Forces Committee since 1998 and was elected its chair in 2006, a post he had held to date. He has also been a member of Representative Body since 2006. He has represented the BDA nationally on the British Medical Association's (BMA) Armed Forces Committee since 1998 and is also on the BMA's Co-ordinating Group.

\title{
GUM HEALTH AND CARDIOVASCULAR EVENTS
}

Conflicting research has been published to support and disprove the theory that the management of gum disease is associated with better prevention of cardiovascular events such as heart attacks and strokes.

A recent study from Chen et al. ${ }^{1}$ suggests there is a link between professional removal of plaque through tooth scaling and a reduced risk of cardiovascular disease. Twenty-two thousand Taiwanese adults aged 50 years and over were involved in the study, which reflected that those who had attended at least one deep cleaning appointment in the past year were significantly less likely to suffer heart attacks or strokes over the next seven years. Only $1.6 \%$ of the exposed group who had received tooth scaling suffered a heart attack in the years to follow compared with $2.2 \%$ of the non-exposed group who had not received a deep clean. Similarly, the percentage of those in the exposed group who had experienced strokes was lower than in the non-exposed group at $8.9 \%$ and $10 \%$ respectively. Those who received tooth scaling more than once in the two year followup period decreased the risk of cardiovascular events further.

This study has numerous limitations, however, which have been recognised by the authors. Whilst age, gender, diabetes, hypertension, hyperlipidaemia and history of coronary artery disease were considered in the study, weight, smoking habits and family history were not noted. Chen's positive correlation between periodontal care and reduced heart failure could be undermined be the general argument that those who are more acutely aware of oral health may take better care of themselves overall, resulting in a healthier heart as a by-product.
This view is taken by the American Heart Association, who has released a statement amid intensifying debate, advising that there is no scientific proof that periodontal interventions will reduce the risk of heart disease. ${ }^{2}$ The two share common risk factors, such as age and smoking, thus inextricably linking the disorders through causality, but that does not mean management of one can prevent the other. Furthermore, gum disease and cardiovascular events occur in both smokers and non-smokers and all other risk and non-risk associated groups. Medical literature from 1950 to July 2011 was searched and examined for relevance to the report, yielding 473 articles that met the inclusion criteria. Results did not offer conclusive evidence of a direct cause and effect relationship between periodontal and cardiovascular disease, though an association between the two independent of joint risk factors was noted in many studies.

The American Association for Dental Research has stressed the importance of the AHA review as an impressive and comprehensive analysis of the current literature. ${ }^{3}$ However, in this response the AADR also notes the need for further research, highlighted by the gaps in scientific understanding in this field.

1. Chen $Z Y$, Chiang $C H$, Huang $C$ C et al. The association of tooth scaling and decreased cardiovascular disease: a nationwide population-based study. Am J Med 2012; Epub ahead of print.

2. Lockhart P B, Bolger A F, Papapanou P N et al. Periodontal disease and atherosclerotic vascular disease: does the evidence support an independent association?: A scientific statement from the American Heart Association. Circulation 2012; Epub ahead of print.

3. American Association of Dental Research AADR press release. Review validates association between oral health and heart health: highlights need for further research. Online article at http://www.iadr. org/files/public/12AADRPressRelease_ AHAStatement.pdf (last accessed April 2012).

By Laura Pacey 